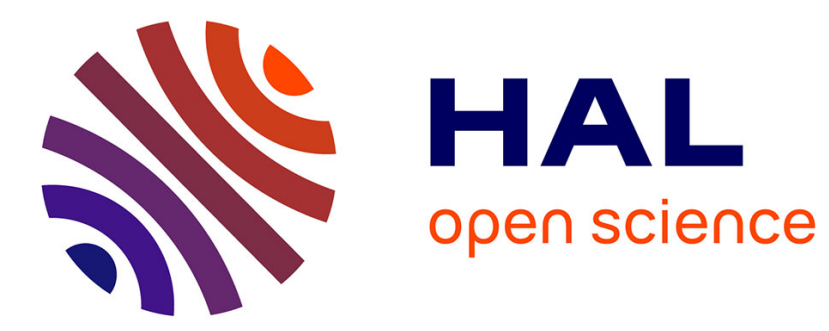

\title{
Pseudopaleosecular variation due to remanence anisotropy in a pyroclastic flow succession
}

\author{
J. Gattacceca, Pierre Rochette
}

\section{To cite this version:}

J. Gattacceca, Pierre Rochette. Pseudopaleosecular variation due to remanence anisotropy in a pyroclastic flow succession. Geophysical Research Letters, 2002, 29 (8), pp.127-1-127-4. 10.1029/2002GL014697 . hal-03036447

\section{HAL Id: hal-03036447 https://hal.science/hal-03036447}

Submitted on 27 Jan 2021

HAL is a multi-disciplinary open access archive for the deposit and dissemination of scientific research documents, whether they are published or not. The documents may come from teaching and research institutions in France or abroad, or from public or private research centers.
L'archive ouverte pluridisciplinaire HAL, est destinée au dépôt et à la diffusion de documents scientifiques de niveau recherche, publiés ou non, émanant des établissements d'enseignement et de recherche français ou étrangers, des laboratoires publics ou privés. 


\title{
Pseudopaleosecular variation due to remanence anisotropy in a pyroclastic flow succession
}

\author{
Jerome Gattacceca ${ }^{1,2}$ and Pierre Rochette ${ }^{2}$ \\ Received 9 January 2002; revised 13 February 2002; accepted 13 February 2002; published 30 April 2002.
}

[1] In order to check the reliability of a paleosecular variation record in a sequence of pyroclastic rocks (Miocene, Sardinia), we measured various types of anisotropy: magnetic susceptibility (AMS), anhysteretic remanent magnetization (AARM) and thermoremanent magnetization (ATRM). The main magnetic carrier is pseudo-single domain titanomagnetite. No general relation appears between the degrees of AMS and AARM, while the degrees of AARM and ATRM are almost identical. Measuring the AARM thus provides a fast and reliable method to correct paleomagnetic deviation in volcanic rocks. Once corrected for anisotropy deviation the apparent scatter of the paleomagnetic directions, mostly on inclination, is drastically reduced. INDEX TERMS: 1518 Geomagnetism and Paleomagnetism: Magnetic fabrics and anisotropy; 1522 Geomagnetism and Paleomagnetism: Paleomagnetic secular variation; 1525 Geomagnetism and Paleomagnetism: Paleomagnetism applied to tectonics (regional, global)

\section{Introduction}

[2] The basic principle behind paleomagnetic studies of volcanic rocks is that their characteristic remanent magnetization (ChRM) is parallel to the local geomagnetic field during the cooling. This is generally true but various mechanisms can bias the recorded magnetic direction. Magnetic anisotropy is one of them as it can result in a deviation of the recorded field towards the plane of maximum alignment of the magnetic grains. In tectonic applications using volcanics rocks a basic requirement is also to check that a proper averaging of paleosecular variation on e.g. a pile of flows is obtained to discuss deviation of the mean direction with respect to geocentric axial dipole predicted direction. The purpose of our contribution is to demonstrate in a case study that variable anisotropy of remanence can lead to an apparent paleosecular variation (PSV) on a sequence of rapidly emplaced flow, i.e. recording in fact only one geomagnetic field direction.

[3] For pseudo-single domain titanomagnetite grains (the most common ferrimagnetic phase in volcanic rocks [Dunlop and Özdemir, 1997]), the magnetic anisotropy is directly linked to the shape anisotropy of the magnetite grains and their petrofabric [Rochette et al., 1992]. In pyroclastic flows, this anisotropy derives from the flow processes during emplacement and from welding after emplacement. For metric to plurimetric flows, welding occurs at temperature above $\approx 600^{\circ} \mathrm{C}$ [Riehle, 1973]. The petrofabric of a welded pyroclastic flow is thus entirely acquired above the Curie temperature of titanomagnetite $\left(\leq 585^{\circ} \mathrm{C}\right)$.

[4] For rocks with horizontal planar fabric (like volcanic and sedimentary rocks) natural TRM deviation can be corrected by measuring the anisotropy of thermoremanence (ATRM) acquisition: $\tan \mathrm{I}_{\mathrm{r}}=\operatorname{tanI}_{\mathrm{g}} / \mathrm{P}_{\mathrm{TRM}}\left(\mathrm{I}_{\mathrm{r}}\right.$ : paleomagnetic inclination recorded by

\footnotetext{
${ }^{1}$ Istituto Nazionale di Geofisica e Vulcanologia, Roma, Italy.

${ }^{2}$ Cerege, UMR 6635, University of Aix-Marseille 3, France.
}

the rock, $\mathrm{I}_{\mathrm{g}}$ : inclination of ambient field during cooling, $\mathrm{P}_{\mathrm{TRM}}$ : degree of ATRM). However ATRM is much more delicate to measure than the widely used anisotropy of magnetic susceptibility (AMS). Uyeda et al. [1963] proposed that $\mathrm{P}_{\mathrm{TRM}}$ is the square of the degree of AMS ( $\left.\mathrm{P}_{\mathrm{AMS}}\right)$. From measurements on gabbros and granites containing multidomain magnetite grains Cogné [1987] established the empirical relations $\mathrm{P}_{\mathrm{TRM}}=\mathrm{P}_{\mathrm{MS}}^{1.81}$ and $\mathrm{P}_{\mathrm{TRM}}=\mathrm{P}_{\mathrm{MS}}^{1.94}$ respectively, close to the theoretical $\mathrm{P}_{\mathrm{TRM}}=\mathrm{P}_{\mathrm{MS}}^{2}$. In sedimentary rocks the anisotropy of anhysteretic remanence (AARM) has been proposed to provide a quantitative correction for inclination error [Jackson et al., 1991; Kodama and Sun, 1992], and Collombat et al. [1993] have observed that $\mathrm{P}_{\mathrm{ARM}} \approx \mathrm{P}_{\mathrm{MS}}^{2}$.

[5] Although AMS is often invoked as a criterion to evaluate the possibility of occurrence of ChRM deviation in volcanic rocks (e.g. [Beck et al., 2001]), this test is valid only if both magnetic suceptibility and ChRM are carried by multidomain magnetite grains. AARM may be a better candidate to evaluate ATRM [Jackson, 1991]. In this paper, we present the results of experimental measurements of AMS, AARM and ATRM on pyroclastic rocks containing mostly pseudo single-domain magnetite grains in order to establish a relation between these parameters and secure the evaluation of the paleomagnetic direction deviations.

\section{Experimental Procedures}

[6] AMS was measured using both KLY-2 and KLY-3 apparatus from AGICO following standard procedures. Bivariate statistics [Henry and Le Goff, 1995] was used to process the data.

[7] To evaluate AARM, after a first demagnetization with a 90 $\mathrm{mT}$ alternating field, samples were given an ARM using a steady $50 \mu \mathrm{T}$ field (intensity close to geomagnetic intensity) and a $70 \mathrm{mT}$ alternating field. The ARM was measured with a $2 \mathrm{G}$ enterprise DC Squid cryogenic magnetometer. Samples were then demagnetized with a $90 \mathrm{mT}$ alternating field and the residual magnetization was measured. These operations were repeated along the three perpendicular axes of the sample. For each step, the difference between the ARM and the residual magnetization provides three components. The total 9 components allow defining the AARM second rank tensor. Eigenvalues and eigenvectors were then determined from this tensor in order to determine the maximum, intermediate and minimum axis of the anisotropy ellipsoid $\left(\mathrm{K}_{1}, \mathrm{~K}_{2}, \mathrm{~K}_{3}\right.$ respectively) as well as their relative norms. This three-position procedure is described in more details by Stephenson et al. [1986]. The 3 -axis method does not take into account possible gyroremanent contributions to the transverse components. In this study gyroremanence should be negligible considering the rather strong anisotropy ratios, and as no spurious behaviour was observed during alternating field demagnetization of the NRM up to $100 \mathrm{mT}$. But for rocks with lower anisotropy and significant single-domain grains contribution, gyroremanence must be considered as a potential bias.

[8] ATRM was measured with the same three-position procedure. After a first heating in a field free environment, TRM was given along each axis by applying a $50 \mu \mathrm{T}$ steady field during the cooling of the sample. Heating and cooling were performed under argon atmosphere in a MMTD furnace. The blocking temperatures of all studied samples range from 500 to $580^{\circ} \mathrm{C}$. Samples were thus 
Table 1. AMS and AARM Measurements

\begin{tabular}{lcccccccc}
\hline Flow & $\mathrm{P}_{\mathrm{MS}}$ & $\mathrm{P}_{\mathrm{ARM}}$ & $\mathrm{T}_{\mathrm{MS}}$ & $\mathrm{T}_{\mathrm{ARM}}$ & $\mathrm{I}_{\mathrm{K} 3-\mathrm{MS}}$ & $\alpha_{95}$ K3-MS & $\mathrm{I}_{\text {K3-ARM }}$ & $\alpha_{95}$ K3-ARM \\
\hline MIF0 & 1.075 & 1.308 & 0.77 & 0.82 & 84 & 4.8 & 84 & 6.5 \\
MIF1 & 1.073 & 1.275 & 0.85 & 0.79 & 86 & 3.6 & 85 & 2.2 \\
MIF2 & 1.033 & 1.103 & 0.53 & 0.28 & 85 & 4.1 & 81 & 14 \\
MIF3 & 1.019 & 1.039 & -0.11 & 0.28 & 81 & 20.0 & 66 \\
IRO2 & 1.054 & 1.105 & 0.70 & 0.50 & 84 & 2.0 & 87 & 4.7 \\
\hline
\end{tabular}

$\mathrm{P}_{\mathrm{MS}}, \mathrm{P}_{\mathrm{ARM}}$ : mean AMS, AARM degree; $\mathrm{T}_{\mathrm{MS}}, \mathrm{T}_{\mathrm{ARM}}$ : mean AMS, AARM shape parameter; $\mathrm{I}_{\mathrm{K} 3-\mathrm{MS}}$, $\alpha_{95}$ K3-MS (respectively $\mathrm{I}_{\mathrm{K} 3-\mathrm{ARM}}$, $\alpha_{95}$ K3-ARM): inclination of mean AMS (respectively AARM) $\mathrm{K}_{3}$ axis and associated semi-angle of $95 \%$ confidence cone.

heated up to $600^{\circ} \mathrm{C}$. Magnetic mineralogy stability was checked by measuring low-field susceptibility after each heating step. For some samples, AARM was remeasured after ATRM measurement.

[9] In view of the AARM and ATRM degrees encountered in this study (ranging from 1.06 to 1.40 ) the 3 -axis method described here provides reliable results (even if it does not give indication about statistical errors on individual anisotropy ellipsoid like the 9position measurement scheme [Mc Cabe et al., 1985]). This is evidenced by the good grouping of directional AARM data and by repetitive measurements of some samples, which indicated good reproducibility $\left(\approx 2 \%\right.$ variability on $\left.\mathrm{P}_{\mathrm{ARM}}\right)$.

[10] Cubic and cylindrical samples have been studied with identical results. AMS is described by the anisotropy degree $\mathrm{P}_{\mathrm{MS}}$ [Nagata, 1961] and the shape parameter $\mathrm{T}_{\mathrm{MS}}$ [Jelinek, 1981]. $\mathrm{P}_{\mathrm{ARM}}, \mathrm{T}_{\mathrm{ARM}}$ and $\mathrm{P}_{\mathrm{TRM}}, \mathrm{T}_{\mathrm{TRM}}$ describe the anisotropies of $\mathrm{ARM}$ and TRM respectively.

\section{Results}

\subsection{Correlation Between ATRM and AARM}

[11] All the studied samples are undeformed Miocene pyroclastic rocks from Sardinia (Italy) whose paleomagnetic and stratigraphy study is described elsewhere [Gattacceca, 2001]. Considering the high susceptibilities, ranging from 5 to $12.10^{-3}$ SI, we will consider that diamagnetic and paramagnetic contribution are negligible and that AMS provides the anisotropy of the ferrimagnetic phase only. Isothermal remanent magnetization acquisition indicates a magnetic saturation around 150-200 mT. Thermomagnetic experiments performed with a CS2 apparatus show two Curie temperatures near 350 and $550^{\circ} \mathrm{C}$ whereas

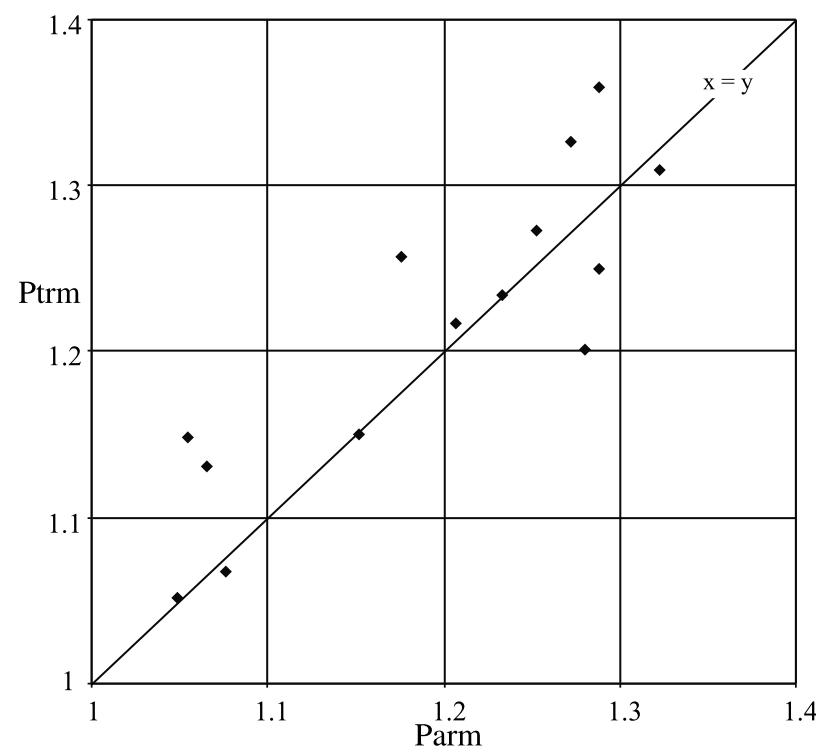

Figure 1. Degree of anisotropy of thermoremanent magnetization versus degree of anisotropy of anhysteretic remanent magnetization for 13 samples from the studied pyroclastic flows. thermal demagnetization curves show unblocking temperatures between 540 and $590^{\circ} \mathrm{C}$. This indicates titanomagnetite as the main magnetic carrier. Hysteresis loop parameters, measured with a home-made hysteresis apparatus at the Institut de Physique du Globe de Paris (Saint-Maur des Fossés, France) indicate pseudosingle domain grains.

[12] Magnetic susceptibility decreased by $20-40 \%$ after the first heating step at $600^{\circ} \mathrm{C}$ in argon atmosphere, and was stable during successive heating steps. Thermomagnetic curves show that this decrease of susceptibility is mainly due to the destruction around $400^{\circ} \mathrm{C}$ of a probable titanomaghemite fraction. After the first heating step, the samples can thus be considered to be in a stable physico-chemical state, with titanomagnetite as the only magnetic carrier.

[13] AARM, ATRM and AMS ellipsoids present nearly vertical minimum directions and strongly planar fabric except for the poorly welded MIF3 flow (Table 1). Values of $\mathrm{P}_{\text {ARM }}$ measured before and after heating at $600^{\circ} \mathrm{C}$ are relatively close: the heating experiments do not disturb too much the magnetic anisotropy. Therefore the measured ATRM is a good estimate of ChRM anisotropy and can be compared with ARM measured before heating. The results displayed on Figure 1 show that $\mathrm{P}_{\text {TRM }}$ is close to $\mathrm{P}_{\mathrm{ARM}}$, suggesting that for our samples AARM is a good proxy to ATRM. This was also observed by Selkin et al. [2000] on a strongly anisotropic anorthosite sample containing single-domain magnetite. It thus appears reasonable to work essentially on the AARM (which is much quicker to measure and excludes mineralogical modifications due to heating) and to extend the conclusions to the ATRM that is the primary parameter to evaluate paleomagnetic deviations in volcanic rocks.

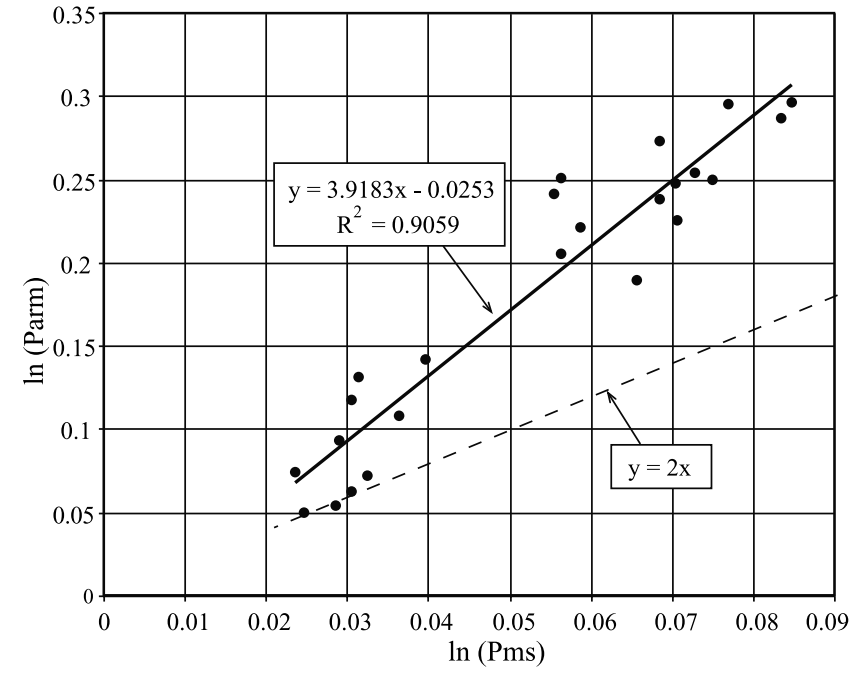

Figure 2. Degree of anisotropy of anhysteretic remanent magnetization versus degree of anisotropy of magnetic susceptibility for flows MIF0-3 from Monte Minerva. The relation between the two parameters is notably different from the relation established for multidomain magnetite grains $\left(\mathrm{P}_{\mathrm{ARM}} \approx \mathrm{P}_{\mathrm{MS}}^{2}\right)$. 


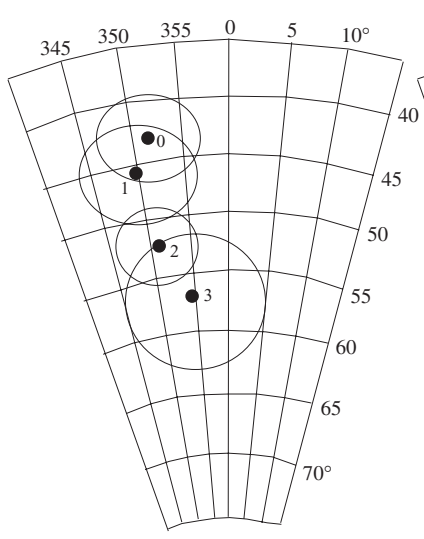

Non corrected

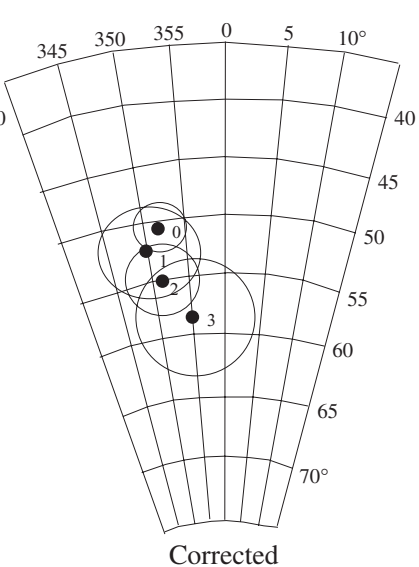

Corrected
Figure 3. Equal area stereographic projection of paleomagnetic directions and relative $95 \%$ confidence cones of pyroclastic flows MIF0-3 before and after correction for inclination shallowing due

\subsection{Monte Minerva: Apparent Secular Variation Due to Anisotropy of Petrofabric}

[14] This set of samples comes from the northern side of Monte Minerva $\left(8^{\circ} 32^{\prime} 28^{\prime \prime} \mathrm{E}, 40^{\circ} 27^{\prime} 28^{\prime \prime} \mathrm{N}\right)$. We measured the anisotropies of flows MIF0 to MIF3. We added a few paleomagnetic directions to the existing dataset (the samples were stepwise demagnetized in alternating field, their magnetization measured with a 2G cryogenic magnetometer, Fisher [1953] statistics were used to process the data). The sub-vertical $\mathrm{K}_{3 \mathrm{MS}}$ axes are in agreement with the absence of a significative tectonic tilt. AARM measurements also give oblate fabrics with subvertical $\mathrm{K}_{3 \mathrm{ARM}}$ axis. Figure 2 displays $\mathrm{P}_{\mathrm{ARM}}$ and $\mathrm{P}_{\mathrm{MS}}$ of the four studied flows. The relation is notably different from $\mathrm{P}_{\mathrm{ARM}}=\mathrm{P}_{\mathrm{MS}}^{2}$ as established for multidomain magnetite grains [Nagata, 1961; Cogné, 1987]. Instead, our results define a relation $\ln \left(\mathrm{P}_{\mathrm{ARM}}\right)=$ $3.92 \ln \left(\mathrm{P}_{\mathrm{MS}}\right)-0.025\left(\mathrm{R}^{2}=0.92\right)$, i.e. $\mathrm{P}_{\mathrm{ARM}} \approx \mathrm{P}_{\mathrm{MS}}^{3.92}$.

[15] The $300 \mathrm{~m}$ thick Monte Minerva pyroclastic succession was emplaced in less than $\approx 100-200 \mathrm{ky}$ as indicated by ${ }^{40} \mathrm{Ar} /{ }^{39} \mathrm{Ar}$ geochronology [Gattacceca, 2001] and confirmed by the rather low scatter of the paleomagnetic directions obtained from the 12 flows composing the succession with a $11.2^{\circ}$ angular standard deviation of virtual geomagnetic poles. Flows MIF0 to MIF3 are a few meter thick and present sharp contacts without visible paleosoils nor erosion evidences. On this basis, it can be hypothesized that these flows were emplaced in a very short time span. In this case, they should have nearly identical paleomagnetic directions. These directions, displayed in Figure 3 and Table 2, are actually close but significantly different. They seem to define a secular variation pattern characterized by an increase of inclination through time. If we consider that, as evidenced in the previous part, the anisotropy of ARM is a good proxy to the anisotropy of TRM, we can correct the paleomagnetic directions for the deviation induced by anisotropy of TRM. As $\mathrm{K}_{3 \mathrm{ARM}}$ is sub-vertical, this deviation is a simple inclination shallowing described by tan $\mathrm{I}_{\mathrm{g}}=$ $\mathrm{P}_{\mathrm{ARM}} \tan \mathrm{I}_{\mathrm{r}}$. Individual paleomagnetic directions are thus corrected following $I_{c}=\tan ^{-1}\left(P_{\text {ARM }} \times \operatorname{tanI} I_{m}\right)$ where $I_{c}$ is the corrected inclination and $\mathrm{I}_{\mathrm{m}}$ the measured inclination. The corrected site mean paleomagnetic directions (Table 2) are almost undiscernible (Figure 3), although it seems that the effect of anisotropy is undercorrected.

[16] This strongly suggests that the four flows were actually emplaced in a time span short with respect to secular variation pattern (i.e. a few tens of years at most), that the proposed paleomagnetic directions correction is valid, and that the observed initial scatter is almost entirely attributable to the effect of anisotropy. The PSV evaluation of Gattacceca [2001] was thus biased.

\subsection{Central Sardinia}

[17] The second set of samples comes from Central Sardinia, Italy $\left(8^{\circ} 52^{\prime} 48^{\prime \prime} \mathrm{E}, 39^{\circ} 53^{\prime} 15^{\prime \prime} \mathrm{N}\right)$ from the pyroclastic flow named IRO2 in Gattacceca [2001]. Samples from this flow display a large scatter of $\mathrm{P}_{\mathrm{MS}}$, from 1.026 to 1.122 . Despite this scatter, paleomagnetic directions are very similar for all samples, and the paleomagnetic mean direction has a high precision parameter $\mathrm{k}=302$ (Table 2). AMS measurements (Table 1) evidence strongly oblate ellipsoids, sub-vertical $\mathrm{K}_{3}$ axes $\left(\mathrm{I}=83.9^{\circ}\right)$ in agreement with the absence of a significative tectonic tilt and a very good grouping of $\mathrm{K}_{1}$ axes indicating a N20E local flow direction. Measurements of anisotropy of ARM also provide a sub-vertical $\mathrm{K}_{3}\left(\mathrm{I}=87^{\circ}\right)$.

[18] Figure 4 shows the relation between $\mathrm{P}_{\mathrm{MS}}$ and $\mathrm{P}_{\mathrm{ARM}}$. The data do not define a clear relation between the two parameters, as it was the case for the flows at Monte Minerva. In particular, even the samples with strong anisotropy of MS $\left(\mathrm{P}_{\mathrm{MS}}>1.10\right)$ have moderate anisotropy of ARM $\left(\mathrm{P}_{\mathrm{ARM}}<1.10\right)$. The corrections to the paleomagnetic directions are thus weak $\left(2-3^{\circ}\right.$ maximum for the inclination). This is coherent with the similar paleomagnetic directions obtained for all samples within the flow and supports the proposed correction method.

\section{Conclusion}

[19] The two studied examples show that there is no simple general relation between the $\mathrm{P}_{\mathrm{MS}}$ and $\mathrm{P}_{\mathrm{ARM}}$ and thus between $\mathrm{P}_{\mathrm{MS}}$ and $\mathrm{P}_{\text {TRM }}$. We attribute this absence of relationship to the different contribution of titanomagnetite grains to ATRM and to AMS according to their size. Small grains contribute much to the TRM but have little influence on the magnetic susceptibility whereas large grains have little influence on the TRM but contribute much to the magnetic susceptibility. Small grains have a stronger remanence intrinsic anisotropy: single-domain grains have an infinite anisotropy while multidomain grains have a finite anisotropy varying with grain shape. Therefore the relation between AMS and ATRM depends on the titanomagnetite grain size spectrum and may even vary within the same flow (IRO2 case).

[20] Therefore, in order to quantitatively estimate ChRM deviations due to anisotropy in volcanic rocks, measuring only the AMS (e.g. [Beck et al., 2001]) is nearly irrelevant. Depending on the grain size spectrum, an anisotropy degree $\mathrm{P}_{\mathrm{MS}}$ of 1.10 can lead

Table 2. Paleomagnetic Directions

\begin{tabular}{lcccccccc}
\hline Flow & $\mathrm{D}^{\circ}$ & $\mathrm{I}^{\circ}$ & $\alpha_{95^{\circ}}$ & $\mathrm{k}$ & $\mathrm{N}$ & $\mathrm{I}^{\circ}{ }_{\mathrm{c}}$ & $\alpha_{95 \mathrm{c}}$ & $\mathrm{k}_{\mathrm{c}}$ \\
\hline MIF0 & 351.8 & 43.1 & 3.8 & 586 & $4 / 4$ & 50.7 & 2.1 & 1915 \\
MIF1 & 350.0 & 46.1 & 4.4 & 90 & $13 / 13$ & 52.4 & 3.9 & 114 \\
MIF2 & 351.0 & 52.3 & 3.1 & 277 & $9 / 9$ & 55.0 & 2.9 & 316 \\
MIF3 & 355.1 & 57.3 & 5.0 & 181 & $6 / 6$ & 58.4 & 4.8 & 196 \\
IRO2 & 162.1 & -36.9 & 2.5 & 302 & $12 / 12$ & -39.8 & 2.4 & 328 \\
\hline
\end{tabular}

D, I: paleomagnetic declination, inclination; $\alpha_{95}, \mathrm{k}$ : Fisher [1953] statistics parameters; N: number of samples; $\mathrm{I}_{\mathrm{c}}$ : paleomagnetic inclination corrected from shallowing; $\alpha_{95 \mathrm{c}}, \mathrm{k}_{\mathrm{c}}$ : statistics parameters after correction of inclination shallowing. 


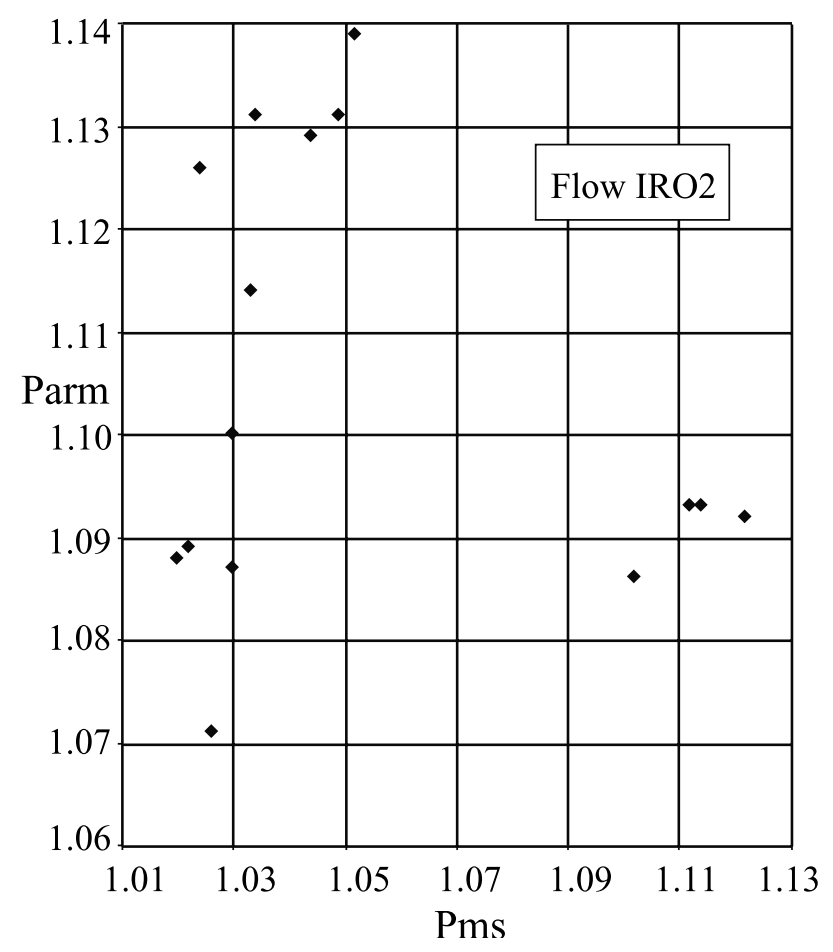

Figure 4. Degree of anisotropy of anhysteretic remanent magnetization versus degree of anisotropy of magnetic susceptibility for flow IRO2 from Central Sardinia.

to an anisotropy degree $\mathrm{P}_{\mathrm{TRM}}$ ranging from 1.08 (Central Sardinia case) to 1.43 (Monte Minerva case), leading to inclination errors of $2^{\circ}$ and $10^{\circ}$ respectively for a paleomagnetic inclination in the range 30 to $60^{\circ}$.

[21] Instead, measuring the degree of AARM gives a rather precise evaluation of the degree of ATRM and allows to correctly evaluate the paleomagnetic deviations in volcanic rocks. This provides a reliable and relatively fast method to check for the occurrence of such deviations which may be responsible for the shallowing of the paleomagnetic inclinations which, in addition to contribute to erroneous plate tectonic reconstructions ([Rochette and Vandamme, 2001]), is commonly interpreted as geomagnetic inclination anomaly, paleosecular variation pattern (e.g. [Gattacceca, 2001]), or large latitudinal drift of the studied terrannes (e.g. [Beck et al., 2001]).

[22] Acknowledgments. Jérôme Gattacceca's stay at INGV was supported by a grant from the French Société de Secours des Amis des Sciences. We are indebted to the paleomagnetism staff of INGV (Roma) and Bernard Henry (Institut de Physique du Globe de Paris, Saint-Maur-
des-Fossés) for their help in the measurements, as well as to C. Aubourg and an anonymous expert for constructive review.

\section{References}

Beck, M. E., R. F. Burmester, D. P. Kondopoulou, and A. Atzemoglou, The paleomagnetism of Lesbos, NE Aegean, and the eastern Mediterranean inclination anomaly, Geophys. J. Int., 145, 223-245, 2001.

Cogné, J. P., TRM deviations in anisotropic assemblages of multidomain magnetite, Geophys. J. R. Astr. Soc., 91, 1013-1023, 1987.

Collombat, H., P. Rochette, and D. V. Kent, Detection and correction of inclination shallowing in deep sea sediments using the anisotropy of anhysteretic remanence, Bull. Soc. Géol. France, 64, 103-111, 1993.

Dunlop, D. J., and Ö. Özdemir, Magnetism of igneous rocks and baked materials, in Rock magnetism: Fundamentals and frontiers, edited by D. Edwards, Cambridge Univertsity Press, Cambridge, 1997.

Fisher, R., Dispersion on a sphere, Proc. R. Soc. London, Sr. A, 217, 295$305,1953$.

Gattacceca, J., Cinématique du bassin liguro-provencal entre 30 et $12 \mathrm{Ma}$. Implications géodynamiques, Ph.D. Thesis, Mémoire des Sciences de la Terre, 41, Ecole des Mines de Paris, Paris, 2001.

Henry, B., and M. Le Goff, Application de l'extension bivariate de la statistique de Fisher aux données d'anisotropie de susceptibilité magnétique: Intégration des incertitudes de mesure sur l'orientation des directions principales, C. R. Acad. Sci. Paris, Sr. IIa, 1039-1042, 1995.

Jackson, M., Anisotropy of magnetic remanence: A brief review of mineralogical sources, physical origins, and geological applications, and comparison with susceptibility anisotropy, PAGEOPH, 136, 1-28, 1991.

Jackson, M., S. Banerjee, and J. Marvin, Detrital remanence, inclination errors and anhysteretic remanence anisotropy: Quantitative model and experimental results, Geophys. J. Int., 104, 95-103, 1991.

Jelinek, V., Statistical processing of anisotrophy of magnetic susceptibility measured on groups of specimens, Studia Geophys. Geodet., 22, 50-62, 1978.

Kodama, K. P., and W. Sun, Magnetic anisotropy as a correction for compaction-caused paleomagnetic inclination shallowing, Geophys. J. Int., $111,465-469,1992$.

McCabe, C., M. Jackson, and B. B. Ellwood, Magnetic anisotropy in the Trenton limestone: results of a new technique, anisotropy of anhysteretic susceptibility, Geophys. Res. Lett., 12, 333-336, 1985.

Nagata, T., Rock magnetism, 2nd edition, Maruzen, Tokyo, 1961.

Riehle, J. R., Calculated compaction profiles of rhyolitic ash-flows tuffs, Geol. Soc. Am. Bull., 84, 2193-2216, 1973.

Rochette, P., M. Jackson, and C. Aubourg, Rock magnetism and the interpretation of anisotropy of magnetic susceptibility, Rev. Geophys., 30, 209-226, 1992

Selkin, P. A., J. S. Gee, L. Tauxe, W. P. Meurer, and A. J. Newell, The effect of remanence anisotropy on paleointensity estimates: A case study from the Archean Stillwater Complex, Earth Planet. Sc. Let., 183, 403-416, 2000.

Stephenson, A., S. Sadikun, and D. K. Potter, A theoretical and experimental comparison of the anisotropies of magnetic susceptibility and remanence in rocks and minerals, Geophys. J. R. Astr. Soc., 84, 185-200, 1986.

Uyeda, S., M. D. Fuller, J. C. Belshé, and R. W. Girdler, Anisotropy of magnetic susceptibility of rocks and minerals, J. Geophys. Res., 68, 279291,1963

J. Gattacceca and P. Rochette, Cerege, BP 80, 13545 Aix-en-Provence Cedex 4, France. (gattacceca@cerege.fr; rochette@cerege.fr) 